\title{
Problem-Oriented Conceptual Model and Ontology for Enterprise e-Recruitment
}

\author{
Saleh Alamro, Huseyin Dogan, Deniz Cetinkaya and Nan Jiang \\ Faculty of Science and Technology, Bournemouth University, United Kingdom \\ \{salamro,hdogan, dcetinkaya,njiang\}@bournemouth.ac.uk
}

Keywords: Enterprise Recruitment, Problem Definition, E-recruitment.

\begin{abstract}
Internet-led labour market has become so competitive forcing many organisations from different sectors to embrace e-recruitment. However, realising the value of the e-recruitment from a Requirements Engineering (RE) analysis perspective is challenging. The research is motivated by the results of a failed e-recruitment project as a case study by focusing on the difficulty of scoping and representing recruitment problem knowledge to systematically inform the RE process towards an e-recruitment solution specification. In this paper, a Problem-Oriented Conceptual Model (POCM) supported by an Ontology for Recruitment Problem Definition (Onto-RPD) for contextualisation of the enterprise e-recruitment problem space is presented. Inspired by Soft Systems Methodology (SSM), the POCM and Onto-RPD are produced based on the detailed analysis of three case studies: (1) Secureland Army Enlistment, (2) British Army Regular Enlistment, and (3) UK Undergraduate Universities and Colleges Admissions Service (UCAS). The POCM and the ontology are demonstrated and evaluated by a focus group against a set of criteria. The evaluation showed a valuable contribution of the POCM in representing and understanding the recruitment problem and its complexity.
\end{abstract}

\section{INTRODUCTION}

Recruitment is a key strategic opportunity for organisations to achieve a competitive advantage over rivals (Bowen and Ostroff, 2004; Carless and Wintle, 2007). Given talent is rare, valuable, difficult to imitate, and hard to substitute, organisations that better attract this talent to fill their job vacancies should outperform those that do not (Ray et al., 2007). Recruitment is the practice of attracting sufficient numbers of qualified individuals on a timely basis to fill job vacancies within an organization (Ahamed and Adams, 2010). It ensures the initial high quality abilities of recruits necessary for work performance (Rynes and Cable, 2003). It also supports a balanced diverse set of recruits to meet organisation's strategic, legal and social goals in regards to the demographic composition of its workforce (Gatewood et al., 2008).

The internet-driven global labour markets become very competitive due to higher educational level of the new generations, strong economic situations and low unemployment rates (Tresh, 2008; Pfieffelmann et al., 2010). This, in turn, puts a great deal of pressure on organisations from different sectors to change their traditional recruitment practices towards more innovative, highquality, customised, and timely e-recruitment solutions (Pfieffelmann et al., 2010). In the military sector, for instance, the migration from old compulsory military recruitment to an all-volunteer force relying on labour market has increasingly pushed the military organisations to get into the continuum (Tresh, 2008; Smaliukiene and Trifonovas, 2012). E-recruiting is defined as any recruitment practice that an organization conducts using web-based solutions (Kim and O'Connor, 2009). Despite the different methods of e-recruiting, web recruiting (i.e. use of corporate web site) is the most commonly used e-recruiting method (Ahamed and Adams, 2010). E-recruiting can bring value for organisations including being reliable in attracting a diverse and qualified group of job seekers, agility in filling vacancies, cost-effectiveness, rapidly response to job seekers' changing needs and market opportunities, and flexibility in normal and exceptional circumstances (Alamro et al., 2015).

The current maturity of information and communication technologies (ICTs) and the recent developments in design processes have ensured a 
relatively simple and reliable transforming of the conventional recruitment practice into e-recruitment solution (Smaliukienè and Trifonovas, 2012). However, to be innovative, the focus should be shifted from the e-solution space into the problem space where the desired effects (i.e. requirements) that an organisation wishes to be brought by the esolution in the recruitment practice exist (Bray, 2002). With the help of Requirements Engineering (RE), the RE activities of the e-solution must be anchored to the domain knowledge of real-world recruitment problem so that the quality of the esolution to be delivered can then be analysed (Martin and Sommerville, 2004; Siegemund, 2014). This front-end part of RE is called problem definition (Jackson, 2001; Fouad, 2011). However, in large-scale, trans-national and multidemographical organisations that are engineeringfocused and need reliable and long-lasting esolutions, the problem definition is very complex and prone to failure (Kossmann and Odeh, 2010; Siegemund, 2014). The research was originally driven by the challenges faced in realising the value of a real e-recruitment project from the military sector referred to as Secureland Army Enlistment. Three main challenges that are related to some knowledge gaps in the research literature can be summarised as:

- The difficulty in scoping recruitment problem (Saks, 2005; Breaugh, 2012);

- The difficulty in representing and understanding of real-world recruitment problem (Ployhart, 2006; Gatewood et al., 2008); and

- The difficulty in systematically transforming the problem domain knowledge into the specification of e-recruitment (Martin and Sommerville, 2004; Siegemund, 2014).

The practical problem addressed in this paper is that the ill-representation and understanding of recruitment problem impedes the realisation of the value of e-recruitment. Therefore, the paper proposes a Problem-Oriented Conceptual Model (POCM) for conceptualising the recruitment problem space from an enterprise perspective supported by an Ontology for Recruitment Problem Definition (Onto-RPD). During this study, three case studies, including the Secureland Army Enlistment, are analysed, and various problems are identified to develop the conceptual model and the corresponding ontology. This work provides a valuable contribution into the understanding of recruitment problem from different perspectives, and can deliver guidance in a systematic manner to inform the requirements elicitation and analysis towards erecruitment solutions.

The paper is organised as follows: this section presents an introduction to the research study. The literature review and background information are presented in Section 2. The case studies are explained and analysed in Section 3. Based on these case studies, the POCM and Onto-RPD are proposed in Section 4. The integration of the model into the recruitment RE process and the results are discussed in Section 5. Finally, conclusions are drawn and future work is suggested in Section 6.

\section{RECRUITMENT AND E- RECRUITMENT}

A great deal of research from both Human Resources (HR) and Industrial and Organisational (I/O) psychology domains has been conducted to define recruitment. However, there has been no consensus on its definition. Randall (1987) states that recruitment is "the set of activities through which the people and the organisations can select each other based on their own best short and long term interests". This definition highlights recruitment from the perspectives of the two key players: organisation (i.e. employer) and people (i.e. job seekers). However, from an organisation-based perspective, Barber (1998) defines recruitment as "the practices and activities carried on by the organization with the primary purpose of identifying and attracting potential employees". He delineated three phases of recruitment: (a) generating applicants, (b) maintaining applicant status, and (c) influencing job choice decisions.

Looking to recruitment from a broad sense, Philips and Gully (2015) define strategic recruitment as "the practices that are connected across the various level of analysis and aligned with firm goals, strategies, context, and characteristics". They suggest that strategic recruitment overlaps with four complex disciplines: Resource-Based Theory (RBT); Strategic Human Resources Management (SHRM); Human Capital; and levels of analysis (Philips and Gully, 2015). This work highlights the need to extend the focus on recruitment from a higher level of analysis as same as the SHRM approach.

E-recruitment is defined as the use of the internet to attract potential employees to an organization and hire them. According to (Ahamed and Adams, 
2010), E-recruitment is "the practice whereby the online technology is used particularly websites as a means of attracting, assessing, interviewing, and hiring personnel". E-recruitment could be defined as any recruiting process that an organization conducts using Web-based tools (Kim and O’Connor, 2009).

\subsection{Problem-Oriented RE}

The concept of problem is central in research on systems and software engineering (Jackson, 2001). A problem is an undesirable situation that is significant to and may be solvable by some agent, although probably with difficulty (Smith, 1989). A problem-oriented view of RE namely problem definition refers to how problems or concerns are represented: what problem elements should be included, what relationships among these elements are, and how these selections might vary over problem types (Smith, 1989; Jackson, 2001).

Such a problem representation is created for structuring problem domain knowledge and orienting it towards RE in a systematic manner (Martin and Sommerville, 2004; Kossmann and Odeh, 2010). Hence, it offers an established problem definition and serves as a basis for eliciting and reasoning about requirements from different stakeholders perspectives (Martin and Sommerville, 2004; Zachman, 2008). Given the complexity of a real-world problem, there is no representation model by which the various elements that constitute a problem can be comprehensively included (Pedell et al., 2014). Hence, each model has some advantages and limitations.

One key example of problem representation techniques is goal modelling (Kavakli, 2004). Goal modelling is based on the premise that in collaborative work situations, people are aware of and share common goals and act towards their fulfilment (Fouad, 2011). Hence, the problems associated with business structure, resources, processes, and their supporting systems that inhibit the achievement of these goals can be defined (Kavakli, 2004). However, a real-world problem concerns the goals of humans which are not simple to model for several reasons: (a) they are not known in advance; (b) they are often abstract and imprecise and can evolve during the life of a project; and (c) the means that lead to goal achievement are not known beforehand. Another example is the problem frames (Jackson, 2001), in which frequently occurring problem structures are identified and related to a problem frame. This frame captures the characteristics and relationships of the parts of the world it is concerned with, and the concerns and difficulties that are likely to arise. This helps to focus on the problem space instead of moving into the solution space. However, it is criticised being limited in scope focusing on the objective aspects of software problems (Hall et al., 2008).

A third problem representation technique is Enterprise Architecture (EA). An EA, e.g. Zachman Framework (Zachman, 2008), provides a structure (i.e. representation) that establishes a reference of problem definition and guides the transformation process (i.e. methodology) towards the solution. However, they are built on a faulty argument that a real-world problem can be analogously represented using the conventional architecture representations of the manufacturing and constructions, which make the social and subtle features often neglected or trivialised (Pedell et al., 2014).

\subsection{Representation of the Recruitment Problem}

There are a number of descriptive and prescriptive recruitment models proposed for conceptualising recruitment problem. The most cited ones are Rynes and Cable's (2003) model for future recruitment research, Saks's (2005) dual-stage model of the recruitment process, and Breaugh and Starke's (2008) model for the organizational recruitment process. While these models address some aspects of recruitment problems, they are strongly solutionoriented, focusing on what and how rather than why. Ployhart (2006) comments on the research-practice gap of recruitment saying "it seems organisational decision makers do not understand staffing (recruitment) or use it optimally". It has been widely suggested that a better representation of the recruitment problem relies in the first instance on an appreciation of its complexity (Rynes and Cable, 2003; Saks, 2005; Breaugh and Starke, 2008). This complexity stems from a set of cognitive, social and organisational variables involved and the nature of their relationships (Breaugh, 2012).

This paper proposes an established conceptualisation of recruitment problem that describes the various problem elements and their relationships, and shows how these problem concepts might vary over different types of recruitment problems. Hence, the depiction of the constituent elements of recruitment problem and their overlapping relationships is the essence of the representation of recruitment problem. This representation will help closing the gap in different 
ways. It will support delaying of solution consideration until a good understanding of the problem space is gained. It will also provide a means of analysing and decomposing problems into simpler sub-problems that can be readily addressed. It will also help stakeholders to capture and share the necessary problem domain knowledge, and this will be driven into the negotiation over trade-offs and consideration of details of the solution support.

\section{RESEARCH METHODOLOGY}

The research method used is design science. According to (Hevner et al., 2004), design science creates new artefacts for solving practical problems. These artefacts can be methods, models, constructs, frameworks, prototypes or IT systems, which are "introduced into the world to make it different, to make it better" (Johannesson and Perjons, 2014). The design science research process carried out in this research included five research activities as defined by the design science method framework of (Johannesson and Perjons, 2014). These activities and their application are presented below.

\subsection{Problem Explication}

The first activity in the design science process is to explicate the practical problem that motivates why the artefacts, in our case the POCM (ProblemOriented Conceptual Model) and the corresponding Onto-RPD (Ontology for Recruitment Problem Definition, need to be designed and developed. The practical problem is the ill-representation and understanding of recruitment problem impedes the realisation of the value of e-recruitment. This problem has been faced in Secureland Army Enlistment project which denotes a knowledge gap in the literature. Hence, the abovementioned artefacts are designed to solve this problem.

\subsection{Requirements Definition}

The second activity in the design science process is to define the requirements of the POCM and its detailed Onto-RPD. These requirements will be used as a basis to evaluate the resulting artefacts and guide the construction process of them in addition to any refinement steps. Based on the literature review, the following requirements are selected:

- The artefact(s) should be comprehensive. Comprehensiveness is the degree to which the artefact(s) offers complete knowledge (Viller and Sommerville, 2000; Fox et al., 1998). Osada et al. (2007) refer to this as the amount of suitable information.

- The artefact(s) should be generic. Generality is the degree to which the artefact(s) is shared and sector/domain-independent (Fox et al., 1998). The artefact(s) should be shared between diverse stakeholders and activities and not specific to a sector (Vesely, 2011).

- The artefact(s) should be precise. Precision is the degree to which the artefact(s) has correct and accurate definitions compared to the existing domain knowledge (Fox et al., 1998; Osada et al., 2007).

- The artefact(s) should be abstract / granular. Abstraction or granularity is the degree to which the artefact(s) represents a core set of primitives that are partitionable in different levels (Viller and Sommerville, 2000; Fox et al., 1998; Osada et al., 2007).

- The artefact(s) should be perspicacious. Perspicacity is the degree to which the artefact(s) is easily understood by the practitioners so that it can be consistently interpreted across the enterprise (Fox et al., 1998).

\subsection{Design and Development}

This third activity is to design and develop the artefacts that address the explicated problem and fulfils the defined requirements, in this case design and develop the POCM and Onto-RPD. The design and development is described in section 4 .

\subsection{Demonstration and Evaluation}

This activity is to use and assess how well the artefacts solve the practical problem taking into account the previously identified requirements. We have evaluated the POCM and Onto-RPD by conducting a focus group of experts from heterogeneous recruitment-related domains. The results are presented in section 5 .

\section{DEVELOPMENT OF POCM AND ONTO-RPD}

The POCM and Onto-RPD were developed by means of applying Soft Systems Methodology (SSM) (Checkland and Poulter, 2010) as an approach upon three case studies to capture the 
different problem-oriented worldviews and develop root problem definitions. The artefacts were not simply developed by a matter of consolidating partial vocabularies from the literature, but through bottom-up analysis of data using many techniques associated with the development of grounded theory. First, the Secureland Army enlistment case study (case 1) was analysed using many problem analysis techniques (e.g. Rich Picture, CATWOE, 5 Whys, and Cause-Effect analysis). The first version of the POCM was developed in (Alamro et al., 2014). This version, Figure 1, was later refined and supported by a corresponding Onto-RPD, Figure 2, for more elaboration using text analysis from the other case studies: British Army Regular Enlistment (case 2) and UK Undergraduate Universities and Colleges Admissions Service (UCAS) (case 3) respectively. The final POCM, Onto-RPD, root problem definitions are described briefly below. The POCM is illustrated in Figure 1. The problem types extracted from the three case studies to develop the conceptual model are explained in Table 1. Figure 2 represents the ontology of recruitment problem definition.

\section{DEMONSTRATION AND EVALUATION OF POCM AND ONTO-RPD}

In this section, the demonstration and evaluation of the POCM and Onto-RPD are presented.

\subsection{Evaluation}

The evaluation of the POCM and Onto-RPD was carried out with a focus group consisting of 10 experts from different recruitment-related domains (e.g. HR, marketing, psychology, and management). These experts were academic staff and research students from a university in the UK. As an assignment, subjects were required to write a description of a recruitment-related problem situation they faced during the focus group. These descriptions were revised with the corresponding subjects and then circulated to others being asked to carefully state and define the central and primary problem in each case from their perspectives. The answers were collected and prepared for the focus group meeting. A package including the POCM and Onto-RPD, a list of defined terminologies, and a questionnaire with instructions of use were sent to the participants prior to the meeting. The experts were asked upon each case study to discuss the recruitment problems, their relationships, and mapping to the resulting concepts and sub-concepts as incorporated into the POCM and Onto-RPD. A questionnaire was then completed by each expert after the discussion. Root problem definitions with definition of key concepts are elaborated below.

Hardware. A general term that includes the physical elements (i.e. tangible assets) used or produced by a recruitment actor that can be seen, touched, and controlled.

Humanware. A general term that includes all human-related activities carried out by a recruitment actor such as roles, responsibilities, relationships, etc.

Information (conveyed): Described as a problem owned by all recruitment actors in which their own information (including all types of information) cause an impact on the others' interests assessed by a set of quality features (e.g. availability, adequacy, relevance, etc.) taking into account all influences of other problem domains.

Information (Received): Described as a problem owned by all recruitment actors in which the received information (including all types of information) cause an impact on the other problem domains e.g. whom to recruit, recruitware, and timings assessed by a set of quality features (e.g. availability, adequacy, relevance, etc.) taking into account all influences of other problem domains.

Interest. Described as a problem owned by all recruitment actors in which their perceptions of the recruitware, information, and timing influence their intentions to react assessed by a set of factors (e.g. value/expectancy and background factors).

Offer Rejection / Withdrawal / no engagement. Described as problem owned by all recruitment actors in which their behaviours influence the outcomes.

Problem context. The area in which a problem exists.

Problem domain. A way of considering or conceptualising problem.

Recruitment. An enterprise system in which different players interact according to their interests to fill a job vacancy. 


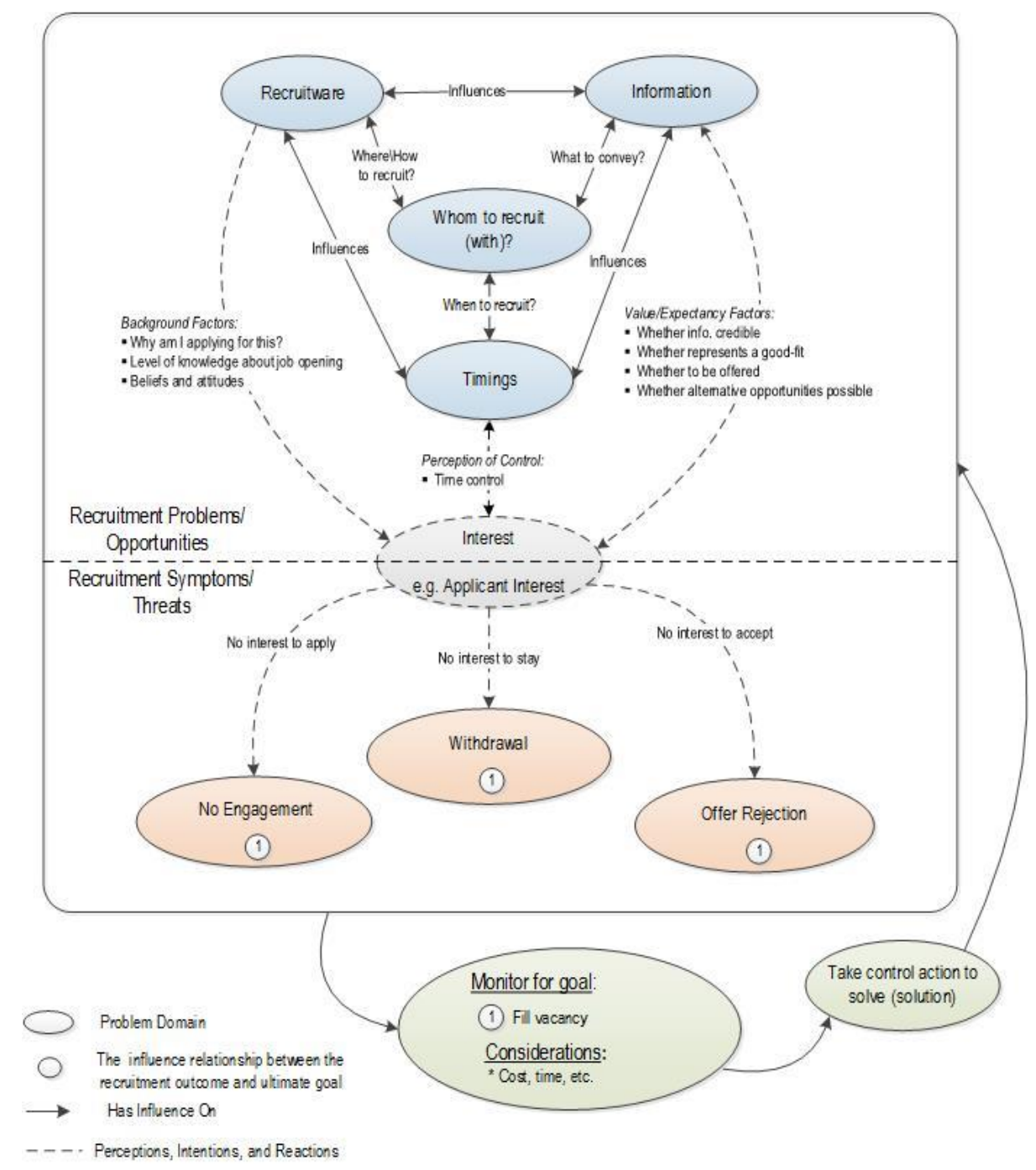

Problem-Oriented Conceptual Model

Figure 1: Problem-oriented conceptual model (POCM) for recruitment problem.

Recruitment Problem. A problematic situation with a recruitment practice regarded as undesired that needs to be defined to overcome.

Recruitware. Described as a problem owned by all recruitment actors in which their own attributes, shaped by a number of elements (including humanware, software, and hardware), cause an impact on the others' interests assessed by a set of quality features (e.g. visibility, usability, fairness, etc.) within the constraints of other problem domains.

Timing. Described as a problem owned by all recruitment actors in which their timings of events cause an impact on the others' interests assessed by a set of quality features (e.g. availability and responsiveness) taking into account all influences of other problem domains.

Whom to recruit (with). Described as a problem owned by all recruitment actors in which their decisions in regard to the optimum recruitment partner to recruit with to fill a specific vacancy influence/influenced by recruitware, information, and timing taken into account the external factors e.g. social, economic, political, technological, legal, and environmental. 
Table 1: Mapping the types of problems from different case studies into the POCM.

\begin{tabular}{|c|c|c|c|}
\hline Category & Case 1 & Case 2 & Case 3 \\
\hline $\begin{array}{l}\text { Recruitware- } \\
\text { Information }\end{array}$ & $\begin{array}{l}\text { Paper-based } \\
\text { announcement restricts } \\
\text { availability of } \\
\text { information }\end{array}$ & $\begin{array}{l}\text { Less visibility of armed } \\
\text { forces needs much } \\
\text { information be disclosed }\end{array}$ & $\begin{array}{l}\text { Different tools with } \\
\text { different modes of } \\
\text { information delivery }\end{array}$ \\
\hline $\begin{array}{l}\text { Recruitware- } \\
\text { Whom to recruit }\end{array}$ & $\begin{array}{l}\text { Job locations are remote } \\
\text { from local applicants. }\end{array}$ & $\begin{array}{l}\text { We try to minimise the } \\
\text { impact of mobility on } \\
\text { applicants. }\end{array}$ & $\begin{array}{l}\text { Improved reach of UCAS } \\
\underline{\text { services across } \underline{\text { social }}} \\
\underline{\text { classes }}\end{array}$ \\
\hline $\begin{array}{l}\text { Recruitware- } \\
\text { Timing }\end{array}$ & $\begin{array}{l}\text { Hard to build a strong } \\
\text { relationship in a short } \\
\text { time. }\end{array}$ & $\begin{array}{l}\text { Loss of timely support } \\
\text { needed by other partners. }\end{array}$ & $\begin{array}{l}\text { Possible adjustment after } \\
\text { exam results (Adjust } \\
\text { service). }\end{array}$ \\
\hline $\begin{array}{l}\text { Timing- } \\
\text { Information }\end{array}$ & $\begin{array}{l}\text { Less time to explore job } \\
\text { opportunities. }\end{array}$ & $\begin{array}{l}\text { Successive provision of } \\
\text { job characteristics offered } \\
\text { during recruitment } \\
\text { process. }\end{array}$ & $\begin{array}{l}\underline{\text { Up-to-date }} \underline{\text { information, }} \\
\underline{\text { advice and guidance }} \\
\underline{\text { IAG). }}\end{array}$ \\
\hline $\begin{array}{l}\text { Whom to recruit- } \\
\text { Information }\end{array}$ & $\begin{array}{l}\text { High probability of being } \\
\text { offered undesired job } \\
\text { because of diversity } \\
\text { considerations. }\end{array}$ & $\begin{array}{l}\text { Some information that } \\
\text { might persuade potential } \\
\text { recruits to enlisting is not } \\
\text { routinely volunteered. }\end{array}$ & $\begin{array}{l}\text { Undesirable divide } \\
\text { between those applicants } \\
\text { who receive effective } \\
\text { advice and those who do } \\
\text { not. }\end{array}$ \\
\hline $\begin{array}{l}\text { Whom to recruit- } \\
\text { Timing }\end{array}$ & $\begin{array}{l}\text { Extra time must be } \\
\text { available for remote } \\
\text { applicants. }\end{array}$ & $\begin{array}{l}\text { Ongoing marketing } \\
\text { campaigns for different } \\
\underline{\text { categories of applicant. }}\end{array}$ & $\begin{array}{l}\text { Predefined deadlines for } \\
\text { different applicants to } \\
\text { apply and reply. }\end{array}$ \\
\hline $\begin{array}{l}\text { Information- } \\
\text { Interest }\end{array}$ & $\begin{array}{l}\text { Only those who are well- } \\
\text { informed about the army } \\
\text { and its structure can } \\
\text { predict the location of job }\end{array}$ & $\begin{array}{l}\text { The terms of service are } \\
\text { extremely confusing and } \\
\text { subject to many } \\
\text { probabilities }\end{array}$ & Clear entry requirements \\
\hline $\begin{array}{l}\text { Recruitware- } \\
\text { Interest }\end{array}$ & $\begin{array}{l}\text { Conceived interest in } \\
\text { defending the country } \\
\text { needs to be met by } \\
\text { reliable enlisting } \\
\text { practices }\end{array}$ & $\begin{array}{l}\text { Negative publicity from } \\
\text { Afghanistan and Iraq } \\
\text { might not persuade } \\
\text { potential recruits to } \\
\text { enlisting }\end{array}$ & $\begin{array}{l}\text { Apply with } 5 \text { course } \\
\text { options }\end{array}$ \\
\hline Timing-Interest & $\begin{array}{l}\text { Post-result recruitment } \\
\text { does not allow much time } \\
\text { to decide }\end{array}$ & $\begin{array}{l}\text { Career appeals } \\
\text { progressively less as } \\
\text { potential recruits grow } \\
\text { into adulthood }\end{array}$ & $\begin{array}{l}\text { Many applicants were } \\
\text { happy with pre-result } \\
\text { application (using } \\
\text { predicted grades) }\end{array}$ \\
\hline
\end{tabular}




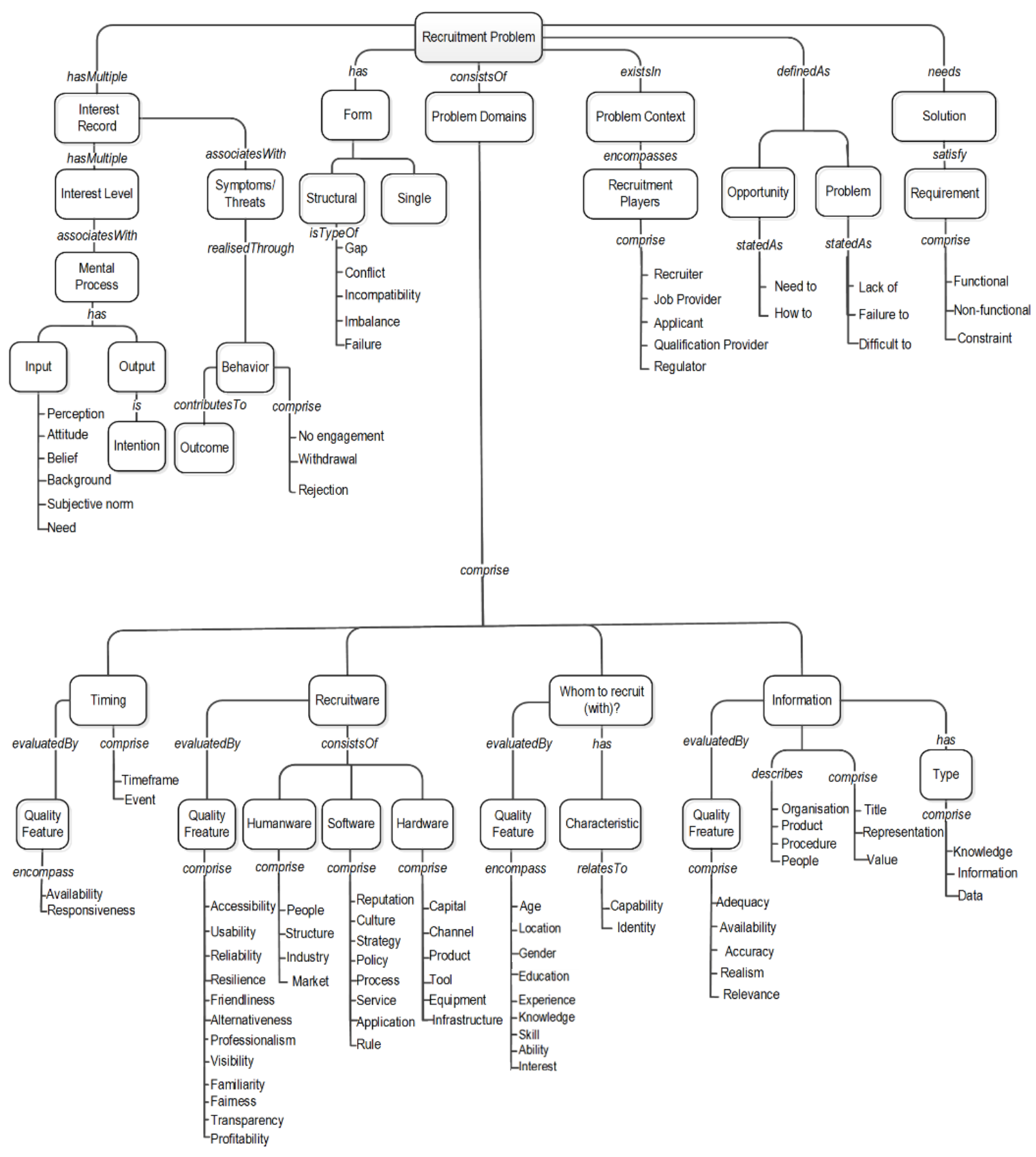

Ontology for Recruitment Problem

Figure 2: The ontology of recruitment problem definition (Onto-RPD). 


\subsection{Key Findings from the Evaluation}

The key findings from the evaluation that is centred on the requirements and characteristics of the model are presented in section 3.2, are as follows:

- Comprehensiveness: three experts clearly confirmed that the POCM and Onto-RPD are complete covering the required knowledge of recruitment domain. For instance, one expert stated "it is impressive, I can say that your models (i.e. POCM and Onto-RPD) are quite full". In contrast, one expert stated that "the two models in addition to the glossary shall be used together for complete knowledge, the POCM was little vague until I referred to the Onto-RPD and glossary".

- Generality: six experts acknowledged that the POCM and Onto-RPD are quite generic but with some comments. One stated "some specificity would be helpful especially with selection and interview processes". Another stated "information domain could be clearer with more specific attributes e.g. job attributes". One also argued "the goal (fill vacancy) needs to be expanded where many stakeholders' goals may exist". However, from an enterprise perspective, we focus on the ultimate shared goal for which all enterprise actors shall cooperate to achieve in order to increase labour market share. While also defining all difficulties and constraints that impede the achievement of this goal from problem-oriented perspective.

- Precision: most of experts agreed that the terms used in the models were quite common and the definitions provided are relatively accurate. However, one expert stated "the term of recruitware is new, it would be better to use more common one". However, the term has been used in the literature and the definition has been agreed on.

- Abstraction / granularity: three experts confirmed that the POCM is abstract and can be applied for problem definition in different level of analysis. One stated "I think this is the best part of the POCM which accounts for why the POCM has been made too generic". Another stated "the core elements of the POCM can be instantiated in different abstraction levels". In contrast, some argue "the POCM is good for management problems".

- Perspicaciousness: five experts confirmed that the POCM and Onto-RPD were easy to understand and promoting problem analysis. One expert commented "many problem scenarios have been applied which makes clear that the POCM and Onto-RPD are very effective in this part". Another stated "I can understand where the conflicts might happen". Moreover, one stated "The POCM and OntoRPD help pose questions that may have been forgotten by a stakeholder". Some argue that it lacks a step-by-step method to define the problem.

\section{CONCLUSIONS}

In this paper, a high-level Problem-Oriented Conceptual Model (POCM) is proposed for conceptualising and synthesizing various problem concepts of the recruitment problem space. The POCM and hence the corresponding Onto-RPD provide a means to better understanding how recruitment problem may emerge, develop, and change over time. POCM also represent and reason about possibly conflicting aspects of the recruitment interests arising from different enterprise recruitment entities. The future work will focus on developing a systematic approach to transition the recruitment problem knowledge that is embedded in the POCM to an e-recruitment requirements specification.

\section{REFERENCES}

Ahamed, S., Adams, A., 2010. Web recruiting in government organisations: A case study of the Northern Kentucky / Greater Cincinnati Metropolitan Region, Public Performance \& Management.

Alamro S., Dogan H., Phalp K., 2015. Forming enterprise recruitment pattern based on problem-oriented conceptual model, Procedia Computer Science, 64, pp. 298-305.

Alamro S., Dogan H., Phalp K., 2014, E-military recruitment: a conceptual model for contextualizing the problem domain. Proceedings of the International Conference on Information Systems Development: Transforming Organisations and Society through Information Systems.

Barber, A., 1998. Recruiting employees. Thousand Oaks, Sage Publications, CA.

Bowen, D.E., Ostroff, C., 2004. Understanding HRM-firm performance linkages: The role of the 'strength' of the HRM system. Academy of Management Review, 29 (2), pp. 203-221. 
Bray, I., 2002. An introduction to requirements engineering. England: Addison Wesley.

Breaugh, J. A., 2012. Employee recruitment: Current knowledge and suggestions for future research. In N. Schmitt (Ed.), The Oxford handbook of personnel assessment and selection, Oxford University Press, pp. 68-87.

Breaugh, J., Starke, M., 2008. Research on employee recruitment: so many studies, so many remaining questions. Journal of Management, 26(3), pp.405-434.

Carless, S.A., Wintle, J., 2007. Applicant Attraction: The role of recruiter function, work-life balance policies and career salience. International Journal of Selection and Assessment, 15(4), pp. 394-404.

Checkland, P., Poulter, J., 2010. Soft systems methodology. Systems approaches to managing change: A practical guide.

Fouad, A., 2011. Embedding requirements within the Model Driven Architecture. PhD Thesis, Bournemouth University.

Fox, M., Barbuceanu, M., Gruninger, M., Lin, J., 1998. An organization ontology for enterprise modelling. In Prietula, M., Carley, L., Gasser, L. (Eds), Simulating Organizations: Computational Models of Institutions and Groups, AAAI/MIT Press, CA, pp. 131-152.

Gatewood, R., Field, H., Barrick, M., 2008. Human resource selection. $6^{\text {th }}$ Edition, South-Western College Pub.

Hall, J. G., Rapanotti, L. Jackson, M.., 2008. Problem oriented software engineering: solving the package router control problem. IEEE Transactions on Software Engineering, 34(2), pp. 226-241.

Hevner A., March S., Park J., 2004. Design science in information systems research. MIS Quarterly, 28 (1), p.75-105.

Jackson, M., 2001. Problem frames: analysing and structuring software development problems. AddisonWesley.

Johannesson P., Perjons E., 2014. An introduction to design science. Springer International Publishing, Switzerland.

Kavakli, E., 2004. Modelling organizational goals: Analysis of current methods. ACM symposium on Applied Computing, Nicosia, Cyprus.

Kim, S., O'Connor, J., 2009. Assessing electronicrecruitment implementation in state governments: Issues and challenges. Public Personnel Management, 35(1), pp. 47-66.

Kossmann, M., Odeh, M., 2010. Ontology-driven requirements engineering a case study of OntoREM in the aerospace context. In INCOSE Conference, Chicago, USA.

Martin, D., Sommerville I., 2014. Patterns of cooperative interaction: linking ethnomethodology and design. ACM Transactions on Computer-Human Interaction, 11(1), pp. 59-89.
Osada, A., Ozawa, D., Kaiya, H., Kaijiri, K., 2007. The role of domain knowledge representation in requirements elicitation, $25^{\text {th }}$ IASTED International Multi-Conference Software Engineering, Innsbruck, Austria, pp. 84-92.

Pedell, S., Miller, T., Vetere, F., Sterling, L., Howard, S., 2014. Socially-oriented requirements engineering: software engineering meets ethnography. In V. Dignum and F. Dignum (eds.), Perspectives on Culture and Agent-based Simulations, Studies in the Philosophy of Sociality 3, Springer Switzerland.

Pfieffelmann, B., Wagner, S., Libkuman, T., 2010. Recruiting on corporate web sites: Perceptions of fit and attraction. International Journal of Selection and Assessment, vol. 18, pp. 40-47.

Phillips, J., Gully, S., 2015. Multilevel and strategic recruiting where have we been, where can we go from here. Journal of Management, 41(5), pp. 1416-1445.

Ployhart, R., 2006. Staffing in the $21^{\text {st }}$ century: New challenges and strategic opportunities. Journal of Management, 32, pp. 868-897.

Randall, S., 1987. Personnel and human resource management. $3^{\text {rd }}$ Edition, West Pub. Co.

Ray, G., Muhanna, W., Barney, J., 2007. Competing with IT: The role of shared IT-business understanding. Communications of the ACM, 50(12), pp. 87-91.

Rynes, S., Cable, D., 2003. Recruitment research in the twenty first century. In W. C. Borman, D. R. Ilgen, et al. (Eds.), Handbook of psychology: Industrial and organizational psychology, vol. 12, pp. 55-76, Wiley.

Saks, A. M., 2005. The impracticality of recruitment research. In A. Evers, O. Smit-Voskuyl, \& N. Anderson (Eds.), Handbook of personnel selection, Basil Blackwell, pp. 47-72.

Siegemund, K., 2014. Contributions to ontology-driven requirements engineering, $\mathrm{PhD}$ Thesis, Technische Universität Dresden.

Smaliukienè, R., Trifonovas, S., 2012. E-recruitment in the military: challenges and opportunities for development, Journal of Security and Sustainability Issues, 1(4), pp. 299-307.

Smith, G., 1989. Defining managerial problems: A Framework for Prescriptive Theorizing. Management Science, vol. 8, pp. 963-981.

Tresch, T., 2008. Challenges in the recruitment of professional soldiers in Europe. In: Vasile, P., Corina, V.,George, R. (eds). Strategic Impact, Romania, National Defence University, vol. 3, pp. 76-86.

Vesely A. Theory and methodology of best practice research: A critical review of the current state. Central European Journal of Public Policy, vol. 2; p. 98-117.

Viller, S., Sommerville, I., 2000. Ethnographically informed analysis for software engineers. IJHCS, 53(1), pp. 169-196.

Zachman, J., 2008. The concise definition of the Zachman framework, link: https://www.zachman.com/aboutthe-zachman-framework. 